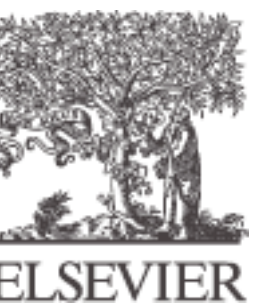

http://www.elsevier.com

\section{HANDBOOK OF KNOWLEDGE REPRESENTATION}

To order this title, and for more information, click here

\author{
Edited By \\ Frank van Harmelen, Vrije Universiteit \\ Amsterdam, The Netherlands \\ Vladimir Lifschitz, University of Texas at \\ Austin, USA \\ Bruce Porter, University of Texas at \\ Austin, USA

\section{Included in series} \\ Foundations of Artificial Intelligence,
}

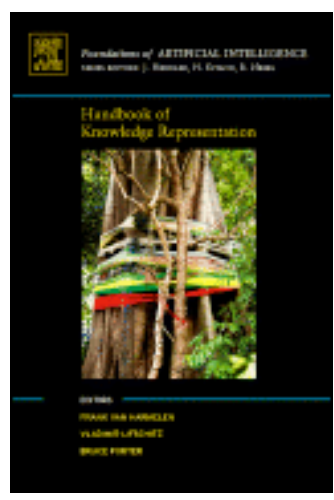

\section{Description}

Knowledge Representation, which lies at the core of Artificial Intelligence, is concerned with encoding knowledge on computers to enable systems to reason automatically. The Handbook of Knowledge Representation is an up-to-date review of twenty-five key topics in knowledge representation, written by the leaders of each field. This book is an essential resource for students, researchers and practitioners in all areas of Artificial Intelligence.

\section{Audience}

Graduate students and researchers in knowledge representation, graduate students and researchers in artificial intelligence, practitioners in artificial intelligence

\section{Contents}

Part I: General Methods in Knowledge Representation and Reasoning 1. Knowledge Representation and Classical Logic 2. Satisfiability Solvers 3. Description Logics 4. Constraint Programming 5. Conceptual Graphs 6. Nonmonotonic Reasoning 7. Answer Sets 8. Belief Revision 9. Qualitative Modeling 10. ModelBased Problem Solving 11. Bayesian Networks Part II: Classes of Knowledge and Specialized Representations 12. Temporal Representation and Reasoning 13. Spatial Reasoning 14. Physical Reasoning 15. Reasoning about Knowledge and Belief 16. Situation Calculus 17. Event Calculus 18. Temporal Action Logics 19.

Nonmonotonic Causal Logic Part III: Knowledge Representation in Applications 20. Knowledge Representation and Question Answering 21. The Semantic Web: Webizing Knowledge Representation 22. Automated Planning 23. Cognitive Robotics 24. Multi-Agent Systems 25. Knowledge Engineering

\section{Bibliographic \& ordering Information}

Hardbound, 1034 pages, publication date: DEC-2007

ISBN-13: 978-0-444-52211-5

\section{Book contents}

- Table of contents

\section{Reviews}

- Submit your review

Bookmark this page

Recommend this

publication

Overview of all books 
ISBN-10: 0-444-52211-5

Imprint: ELSEVIER

Price: Order form

GBP 120

USD 210

EUR 170

Books and book related electronic products are priced in US dollars (USD), euro (EUR), and Great Britain Pounds (GBP). USD prices apply to the Americas and Asia Pacific. EUR prices apply in Europe and the Middle East. GBP prices apply to the UK and all other countries.

See also information about conditions of sale \& ordering procedures, and links to our reqional sales offices.

$077 / 743$

Last update: 17 Mar 2008

(c) Copyright 2007 Elsevier | http://www.elsevier.com 